\title{
THE ADULT ORLAU SWIVEL WALKER-AMBULATION FOR PARAPLEGIC AND TETRAPLEGIC PATIENTS
}

\author{
By I. R. Farmer, R. Poiner, G. K. Rose, O.B.E., F.R.C.S., and J. H. Patrick, F.R.C.S. \\ Orthotic Research and Locomotor Assessment Unit, (ORLAU), The Robert fones and \\ Agnes Hunt Orthopaedic Hospital, Oswestry, Salop $S Y$ Iо $7 A G$.
}

\begin{abstract}
The ORLAU Swivel Walker which has been used by children with spina bifida, has been modified so that it is now being successfully used by spinal cord paralysed patients.
\end{abstract}

Key words: Ambulation; Paraplegic; Tetraplegic; Swivel walker; Adult; Independence.

\section{Introduction}

SWIVEL walkers have been established as a valuable ambulatory device for paediatric paraplegic patients both from a functional and therapeutic point of view for well over Io years (Edbrooke, I970; Rose \& Henshaw, I972; Stallard et al., I978; Sankarankutty et al., I979).

The device ensures intrinsic stabilisation of the patient through a frame which gives three-point fixation of hips, knees and ankles; extrinsic stabilisation being provided by a pair of swivelling footplates mounted beneath the body frame. Such is the level of overall stability that patients are able to stand and walk without the use of crutches or other walking aids. Ambulation is achieved by sideways rocking of the trunk so that one footplate clears the ground, the mechanics being arranged so that when this happens the frame automatically swivels forward on the grounded footplate. Thus as rocking continues the device indexes forward alternately on each footplate.

Experience has shown that patients are happy to stand in the device for long periods, and this coupled with their ability to walk without other aids led to schools for the handicapped adopting the practice of having children in swivel walkers standing at raised tables to work. This meant that they could ambulate around the classroom to fetch and carry the small items which they may need whilst taking up no more space than a normal child. Whilst speed is slower than for normal walking, the energy expenditure is lower than for most handicapped gait.

It is well recognised that the exercise gained from walking is very beneficial physiologically (Carroll, I974; Rose, 1976) in that it improves urinary drainage, bowel function and circulation, and that the dynamic loading of the skeletal structure which occurs brings about a reduction of spontaneous bone fractures. In addition many patients experience a psychological boost from achieving mobility with an upright stance on a level with their peers.

Mechanical refinements to earlier designs have improved reliability, strength and ease of manufacture (Stallard et al., 1978). In addition it has been made possible for many young patients to achieve independence. This ability is judged very strictly using the following criteria (Rose et al., I98I):

(I) Low energy ambulation at reasonable speed (30-60 per cent of normal for same age). 
(2) Putting on and taking off apparatus without any outside assistance. (Doff and Don.)

(3) Transferring from sitting in wheelchair to standing and vice versa without any outside help. (Transfer.)

One of the features of the new design (The ORLAU Swivel Walker) is that it incorporates modular construction so that kits of parts can be stocked by contractors and assembled to suit individual patient requirements. This has enabled the device to be supplied on a sound commercial basis and it has already been delivered to many parts of the world including the U.S.A. and Australia. The ORLAU Swivel Walker has been available since completion of the first prototype in I975, and since that time nearly 200 spina bifida patients have been supplied.

\section{The Adult Model}

As patients using the ORLAU Swivel Walker grew older it became apparent that many would wish to retain the level of independence which they had achieved. It also became clear that some traumatic paraplegics may be able to benefit from the device. Experience with earlier designs had shown that such adults could cope with this form of ambulation and that they experienced the same psychological and physiological benefits as the children. Consequently an upgraded design to cope with patients with an axilla height in excess of $1000 \mathrm{~mm}$ was developed using the same design philosophy.

The Adult ORLAU Swivel Walker (Fig. I) incorporates a rigid body brace constructed from $I_{2}^{1}{ }^{\prime \prime} \times \frac{3}{4}$ " aluminium alloy channel section, and $\frac{3}{4}$ " diameter tube which is bolted to a $\frac{1}{4}^{\prime \prime}$ baseplate beneath which are mounted the aluminium alloy footplate castings via steel flange pins and double row ball bearings. The footplates are interconnected by a telescopic linkage to keep them parallel for walking, whilst permitting some relative turn when necessary.

Three-point fixation of the hips, knees and ankles is provided by a leather chest pad, polypropylene sacral band, hinged knee bar assembly (with Evazote foam blocks shaped to fit individual patients' knees) and footclamp assembly. The footplates are arranged to provide a good support area which ensures that patients feel secure in their upright stance both for standing and walking.

Since the problems of supply through the normal NHS orthotic arrangements could create difficulty in maintaining consistent quality, the philosophy of modular construction adopted for the smaller version was retained for the adult model. Kits of parts are now stocked by an engineering sub-contractor who assembles them to dimensions of individual patients as measured by an orthotist.

Trials with the first user of the Adult version quickly established that getting into the swivel walker by means of sliding directly from the wheelchair, down the chute with the chest pad, knee bar and footclamp in the open position is as easy for adults as it is for children. However, the extra height of an adult means that their upper limbs are insufficiently long to allow the baseplate of the swivel walker close enough to the wheelchair to permit the final stage of transfer, as practised by many paediatric patients (Stallard et al., 1978). This difficulty was overcome by supplying the patient with detachable upright handles located at the front of the wheelchair arms (Stallard \& Rose, I98I).

\section{Clinical Review}

The first Adult ORLAU Swivel Walker prototype was produced in 1978 and has since had extensive trials. A batch of pre-production prototypes was manu- 


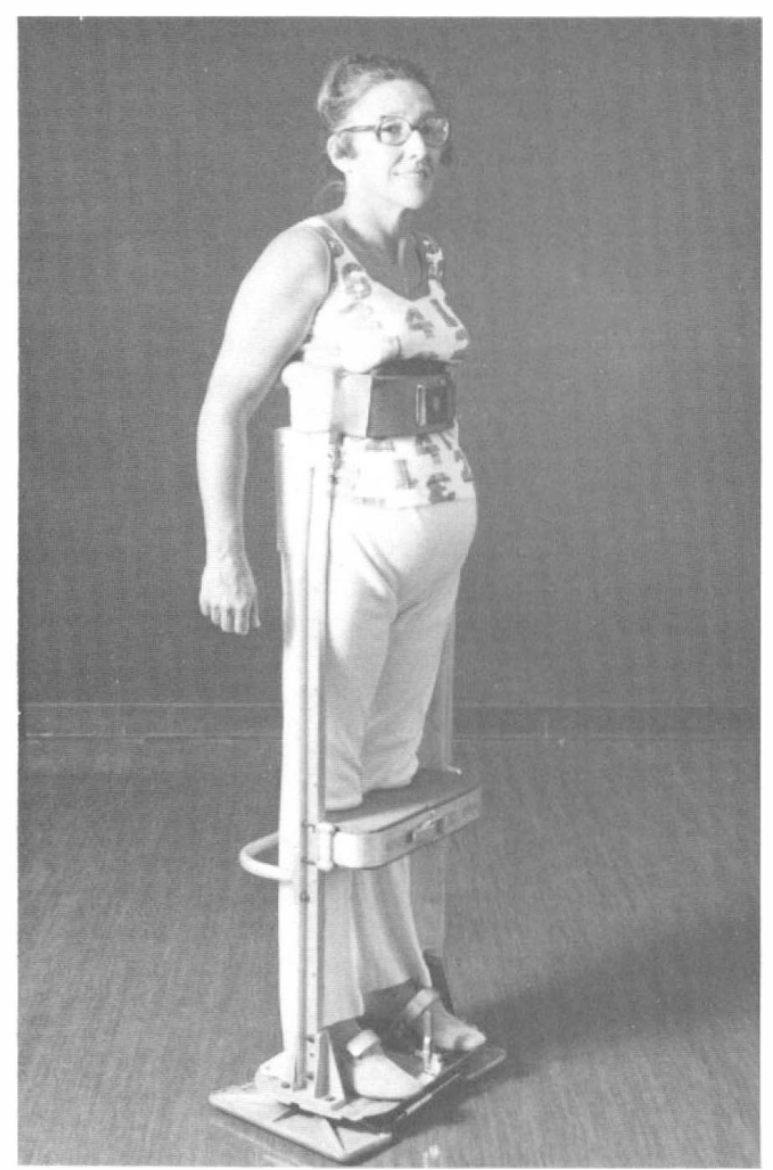

FIG. I

The Adult ORLAU Swivel Walker

factured 18 months later and have been supplied to a number of adult patients. The experience gained with the first five of these adults was sufficiently encouraging for a production version of the Adult model to be initiated. A review of these five patients, all of whom had 6 months' minimum experience in the device, was carried out to establish what benefits they had derived from the use of the Adult ORLAU Swivel Walker. The degree of independence was assessed in terms of their ability to put the appliance on and take it off by themselves, and also to transfer from a wheelchair and vice versa. The age, sex, level and cause of lesion, length of time patients had used a swivel walker, and for traumatic lesions, the time since injury were established and are indicated in Table I.

In order to amplify the experience of each patient a short anecdotal description is added below:

Patient A. This 48-year-old traumatic D6 lesion patient had used a conventional swivel walker for 8 years. She found it of therapeutic benefit in that it helped to relieve leg contractures and improved urinary drainage and bowel function. In addition she was able to more easily undertake some tasks (e.g. washing up and cooking) than in her 
TABLE I

Clinical review of adult users of ORLAU Swivel Walker

\begin{tabular}{|c|c|c|c|c|c|c|c|c|c|}
\hline Patient & Sex & Age & $\begin{array}{l}\text { Level } \\
\text { of } \\
\text { lesion }\end{array}$ & Cause & $\begin{array}{l}\text { Time since } \\
\text { injury }\end{array}$ & $\begin{array}{l}\text { Experience in } \\
\text { swivel walkers }\end{array}$ & $\begin{array}{l}\text { Experience with } \\
\text { Adult ORLAU } \\
\text { Swivel Walker }\end{array}$ & $\begin{array}{l}\text { Independent } \\
\text { doff and don }\end{array}$ & $\begin{array}{l}\text { Independent } \\
\text { transfer }\end{array}$ \\
\hline A & $\mathrm{F}$ & 48 & D6 & Traumatic & 22 years & 9 years & 3 years & Yes & Yes \\
\hline B & $\mathrm{F}$ & 19 & $\mathrm{~L} 2$ & Spina bifida & Congenital & $\begin{array}{l}\text { Intermittent } \\
\text { since }\end{array}$ & 2 years & Yes & Yes \\
\hline $\mathrm{C}$ & $M$ & I6 & Di2 & Spina bifida & Congenital & $\begin{array}{l}3 \text { years old } \\
\text { I } 3 \frac{1}{2} \text { years }\end{array}$ & $2 \frac{1}{2}$ years & Yes & Yes \\
\hline $\mathrm{D}$ & $M$ & I6 & Dio & Spina bifida & Congenital & Io years & $\mathrm{I} \frac{1}{2}$ years & $\begin{array}{l}\text { With a little } \\
\text { help }\end{array}$ & No \\
\hline $\mathrm{E}$ & $\mathrm{F}$ & 29 & C6 & Traumatic & 7 years & 7 months & 7 months & With help & No \\
\hline
\end{tabular}


wheelchair. Living with her parents ensured that she was readily provided with the assistance necessary to doff and don the device and transfer to standing from her wheelchair or bed and vice-versa. However, advancing age began to limit the degree to which her parents were able to cope with the physical effort involved, and an Adult ORLAU Swivel Walker (the first prototype) was built for this patient. It immediately solved the problem of doff and don and gave the patient a feeling of increased stability without inhibiting any of her previous activity. After some experimentation a means of independent transfer to and from her wheelchair was evolved and this has now made her completely independent, thus totally relieving the physical burden on her parents.

Patient B. This I9-year-old spina bifida patient, with a lesion of sensory level L2, had used a swivel walker as a child and virtually given it up in adolescence. However, the availability of the ORLAU Swivel Walker persuaded her to try this form of ambulation once more before going to college, to see if it would enhance her independence. She was able to doff and don and transfer almost as soon as the device was supplied, and now has it at college as an aid to therapy and to perform some functional tasks more suited to an upright posture. It is vital for her that she maintains complete independence because there is no means of assistance available to her during college term time.

Patient C. One of the first patients to use the original swivel walker, this I6-yearold spina bifida patient with a DI2 lesion was able to achieve full independence in the prototype smaller version of the ORLAU Swivel Walker at the age of IO. Being an active boy who derived therapeutic benefit from his swivel walker, and who was able to contribute both at home and in school by performing many tasks (he is very fond of cooking), he was particularly keen not to lose these advantages because of his increased size developed during adolescence. He continues to live at home and maintains full independence of transfer in his new swivel walker.

Patient D. This I6-year-old spina bifida patient with Dio lesion has been a persistent problem, who particularly requires to be kept mobile because of obesity. He has been a user of swivel walkers since early childhood, but the onset of adolescence brought tremendous increase in weight such that it took three physiotherapists to lift him into his apparatus and then get him upright from the floor. Because of his enormous size he could not be supplied with the smaller ORLAU Swivel Walker, but the development of the Adult model has enabled him to take advantage of the design features permitting ease of doff and don. The therapeutic ambulation so vital to this patient is now possible with the assistance of only one physiotherapist, who is able to lift him from the semi-upright position in the wheelchair after the patient has slid into the swivel walker and secured the locations with a minimum of assistance.

Patient E. This 29-year-old C6 traumatic tetraplegic patient had existed in wheelchairs for 7 years after her accident. She was very anxious to be able to stand and ambulate for social reasons, and it was clear that she should derive the usual therapeutic benefits of such exercise. An Adult ORLAU Swivel Walker was prescribed, and on first fitting the patient was apprehensive but happy to be upright. In the following months she developed the ability to ambulate about her house and was delighted to be able to converse with others whilst standing at their level. Because of the extent of her disability, which includes upper limb dysfunction, she is unable to transfer independently, but the ease with which she can be put into the apparatus is much appreciated by her family. Therapeutically she has found a diminishment in leg contractures and says she feels a new physical well-being not experienced since her accident. This young woman had always exhibited a remarkable adjustment to her condition but has clearly received a psychological boost from her new ability to ambulate. 


\section{Discussion}

Experience with adults in the ORLAU Swivel Walker is limited at the present time. However, results with patients who have used the device over a minimum period of 6 months is very encouraging. Those with congenital lesions who have used a swivel walker since childhood are finding that it can continue to be of functional value, if they previously achieved that level of ambulation, and all of them sustain the therapeutic benefits which they experienced as children.

Both the traumatic lesion patients adjusted to swivel walkers soon after supply and are pleased for social reasons with their ability to ambulate without other walking aids. They find being on the same level as others a great relief from constantly sitting in a wheelchair where they are looked down on by those standing around them. In addition the therapeutic advantages of relief of contractures, improvement in urinary drainage and bowel function are much appreciated. Patient A is a long-term user of swivel walkers. She found the improved rigidity of the ORLAU design much to her liking and the ability to transfer vital to her continued use of such a device. None of the design changes interfered with the functional abilities she developed in earlier models. The other traumatic lesion patient is a tetraplegic who finds great therapeutic value in ambulating daily and for whom a new social attitude has developed from being upright and level with others. She has expressed great delight in her new found abilities.

Clearly the ORLAU Swivel Walker is not suitable for every paraplegic or tetraplegic patient, each of whom find their own ways of coping with their very difficult problems. However, experience has shown that many would derive great physiological, psychological, social and functional benefit from such a device. A swivel walker is probably the only device in which a tetraplegic can ambulate, and experience with Patient E indicates that they can benefit as much as the many paediatric patients with upper limb dysfunction who are using the smaller model. With the ease of transfer which can be effected in the ORLAU Swivel Walker, exciting new prospects in the treatment of tetraplegic adults are opened up by the new design. Since many jobs are performed from an upright posture and also require limited mobility (operating machine tools, teletype machines, etc.) it could also improve the employment potential for many of the heavily handicapped.

Because the construction of the ORLAU Swivel Walker is modular it can be supplied to assured engineering standards, from dimensions supplied by an orthotist. At the present time the cost of the appliance is $£ 535$ in ready to fit form, and it is supplied via a charity fund which supports the work of ORLAU. The children's model has been delivered to all parts of the world and already the Adult model has been supplied for research purposes to an American university. Kits of parts are now stocked by an engineering contractor so that supply to any patient requiring the device can be assured.

\section{SUMMARY}

The ORLAU Swivel Walker has been used successfully to provide ambulation for paralysed children over a period of 6 years. To enable them to continue using the device, an Adult version has been developed, and its use by five patients over the age of I6 shows that it can provide useful ambulation for some paralysed adults. In particular, the ability of the patient to stand and move about without crutches etc. widens the employment potential for those who are normally confined to a wheelchair. 


\section{RÉSUMÉ}

Le support ambulatoire à rotule ORLAU est utilisé depuis 6 ans avec succès pour faciliter le déplacement des enfants paraplégiques. Afin de leur permettre de continuer avec son emploi une version adulte a été mise au point, et l'utilisation par 5 patients de plus de I 6 ans indique ses possibilités utiles pour les invalides adultes. Parmi les avantages relevés, la possibilité de se tenir debour et de se déplacer sans béquilles encombrantes etc. permet à l'utilisateur retenu auparavant dans un fauteuil roulant, d'entrevoir une vie plus active au travail.

\section{ZUSAMMENFASSUNG}

Die ORLAU Schwenklaufhilfe wird seit sechs Jahren als Bewegungsmittel für gelähmte Kinder mit großem Erfolg eingesetzt. Um diesen Kindern die Weiterverwendung dieses Gerätes zu ermöglichen, ist nun eine Ausführung für Erwachsene entwickelt worden und dessen Anwendung durch fünf Erwachsene von mehr als sechzehn Altersjahren zeigt, daß das Gerät als ein wertvolles Bewegungsmittel für bestimmte Erwachsenengelähmte eingesetzt werden kann. Besonders die Fähigkeit der Patienten ohne Krücken usw. zu stehen und zu laufen vergrößert das Beschäftigungspotential von Personen, die normalerweise auf die Bewegung mit einem Rollstuhl beschränkt sind.

\section{REFERENCES}

Carroll, N. C. (1974). The orthotic management of the spina bifida child. Clinical Orthopaedics and Related Research, 102, I08-I I4.

Edbrooke, H. (I970). The Royal Salop Infirmary 'Clicking Splint'. Physiotherapy, 56, $4, \mathrm{I} 48-\mathrm{I} 53$.

Rose, G. K. (I976). Surgical/Orthotic management of spina bifida. The Advance of Orthotics, G. Murdoch (Ed.). Edward Arnold, London. 403-4I3.

Rose, G. K. \& Henshaw, J. T. (1972). A swivel walker for paraplegics: medical and technical considerations. Biomedical Engineering, 7, 420-425.

Rose, G. K., Stallard, J. \& Sankarankutty, M. (I98I). Clinical evaluation of spina bifida patients using hip guidance orthosis. Develop. Med. Child Neurol., 23, 30-40.

SankarankutTy, M., Rose, G. K. \& Stallard, J. (1979). The effect of orthotic treatment on spina bifida patients. Spina Bifida Therapy, I, 4, 187-196.

StALlaRD, J. \& Rose, G. K. (I98I). Independence for adult paraplegics in swivel walkers. F. Med. Eng. \& Technol., 5, 3, 136-137.

Stallard, J., Rose, G. K. \& Farmer, I. R. (1978). The ORLAU Swivel Walker. Prosthetics $\mathcal{E}$ Orthotics International, 2, 32-35. 